\title{
Adjusting the electronic properties and gas reactivity of epitaxial graphene by thin surface metallization
}

Jens Eriksson, Donatella Puglisi, Yu Hsuan Kang, Rositsa Yakimova and Anita Lloyd Spetz

\section{Linköping University Post Print}

\section{Tweet}

N.B.: When citing this work, cite the original article.

Original Publication:

Jens Eriksson, Donatella Puglisi, Yu Hsuan Kang, Rositsa Yakimova and Anita Lloyd Spetz, Adjusting the electronic properties and gas reactivity of epitaxial graphene by thin surface metallization, 2014, Physica. B, Condensed matter, (439), 105-108.

http://dx.doi.org/10.1016/j.physb.2013.11.009

Copyright: Elsevier http://www.elsevier.com/

Postprint available at: Linköping University Electronic Press http://urn.kb.se/resolve?urn=urn:nbn:se:liu:diva-105566 


\title{
Adjusting the electronic properties and gas reactivity of epitaxial graphene by thin surface metallization
}

\author{
Jens Eriksson, Donatella Puglisi, Yu Hsuan Kang, Rositza Yakimova, and Anita Lloyd Spetz \\ Department of Physics, Chemistry, and Biology, Linköping University, 58183 Sweden \\ jenser@ifm.liu.se
}

Graphene-based chemical gas sensors normally show ultra-high sensitivity to certain gas molecules but at the same time suffer from poor selectivity and slow response and recovery times. Several approaches based on functionalization or modification of the graphene surface have been demonstrated as means to improve these issues, but most such measures result in poor reproducibility. In this study we investigate reproducible graphene surface modifications by sputter deposition of thin nanostructured Au or Pt layers. It is demonstrated that under the right metallization conditions the electronic properties of the surface remain those of graphene, while the surface chemistry is modified to improve sensitivity, selectivity and speed of response to nitrogen dioxide.

Keywords: Epitaxial graphene on $\mathrm{SiC}$, surface modifications, gas sensor.

\section{Introduction}

Graphene attracts huge interest due to its unique and rich electronic and optical properties [1], such as enormous carrier mobility and optical transparency, as well as flexibility, robustness, environmental stability, and tunable wettability [2]. Graphene research has been predominantly focused on fundamental physics and electronic devices. The potential applications of graphene span a much broader field that includes also sensors, photonics and optoelectronics, where the combination of the optical and electronic properties can be fully exploited.

Graphene gas sensors have been explored since 2007 [3] and impressive sensitivities to various molecules have been achieved in graphene produced by mechanical exfoliation [3], chemical vapor deposition [4], reduced graphene oxide [5], and we have previously demonstrated $\mathrm{NO}_{2}$ detection limits in the low parts per billion (ppb) range for epitaxial graphene on silicon carbide ( $\mathrm{SiC}$ ) [6]. Concomitantly graphene has low selectivity due to high sensitivity to a range of gas molecules, like $\mathrm{NO}, \mathrm{NO}_{2}, \mathrm{CO}, \mathrm{CO}_{2}, \mathrm{NH}_{3}$, and $\mathrm{H}_{2} \mathrm{O}$, which are all of interest for industrial, environmental and medical applications. It also suffers from slow adsorption/desorption, leading to slow response/recovery times.

For graphene-based sensors to become useful it is important to improve selectivity, response/recovery times, and to a certain extent also reproducibility. To that end, several approaches based on surface modifications of the graphene have been investigated. Very impressive detection limits for $\mathrm{NO}$ and $\mathrm{NO}_{2}$ in the range of parts per trillion and even parts per quadrillion have been demonstrated by the use of constant ultraviolet irradiation [4]. However such treatment causes a semi-reversible oxygen functionalization that breaks the $\mathrm{sp}^{2}$ hybridization of 
the graphene [7]. A study by Mao et al. found that the sensitivity to $\mathrm{NO}_{2}$ can be enhanced while suppressing response to other gases like $\mathrm{NH}_{3}$ by decoration with tin oxide nanocrystals [8], though this technique leads to poor time constants and poor reproducibility. A density functional theory (DFT) investigation [9] concluded that impurity doping of graphene by nitrogen or boron can be used to improve sensitivity and selectivity towards CO, $\mathrm{NO}, \mathrm{NO}_{2}$ and $\mathrm{NH}_{3}$, due to increasing the adsorption energy of specific molecules. On the other hand, this approach may not be practical since increasing the adsorption energy increases the recovery time in an exponential manner.

In this study we investigate a reproducible means of functionalizing graphene with nanostructured metals by sputter deposition. Graphene grown by sublimation of $\mathrm{SiC}[10]$ was decorated with thin (nominally $2-5 \mathrm{~nm}$ ) layers of $\mathrm{Au}$ and $\mathrm{Pt}$ and the effect of these metallizations on the electronic properties of the graphene as well as their potential use in controlling gas adsorption and chemical reactions occurring at the graphene surface were investigated. The gas response was tested towards common pollutants from combustion engines and in power plant flue gases, specifically $\mathrm{NO}_{2}, \mathrm{CO}, \mathrm{H}_{2}$, and $\mathrm{NH}_{3}$.

\section{Material and methods}

Large area epitaxial graphene (EG) was prepared by sublimation of $\mathrm{SiC}$ and subsequent graphene formation on semi-insulating, Si-terminated, $4 \mathrm{H}-\mathrm{SiC}(0001)$ on-axis substrates at $2000^{\circ} \mathrm{C}$ in argon and at a pressure of 1 bar [10]. Thin layers $(2-5 \mathrm{~nm})$ of nanostructured $\mathrm{Au}$ or Pt were deposited onto the graphene by direct current magnetron sputtering at room temperature at an elevated pressure of $\approx 50 \mathrm{mTorr}$ and a power of $\approx 100 \mathrm{~W}$.

The effect of the metallization on the electronic properties of the graphene surface were studied by atomic force microscopy coupled with surface potential mapping by scanning Kelvin probe microscopy (SKPM), which can be used to study nanoscale variations in the graphene thickness [11] due to the difference in work function $(\phi)$ depending on the graphene layer thickness. The stability of SKPM measurements relies on the stability of the work function of the probe tips, and is sensitive to the measurement environment, such as humidity. For comparison of relative work function shifts between samples before and after metallization, average $\phi$ values were instead determined by measurements in an ambient Kelvin probe, which determines $\phi$ over a much larger area (determined by the tip radius of $0.5 \mathrm{~mm}$ ). The work function of the tip is calibrated against a gold standard with a known work function and the values calculated are more stable as the tip never comes in contact with the sample, thereby avoiding contamination and tip deformation. Variations in e.g. ambient humidity influence the graphene work function more than that of the gold reference electrode. Therefore only the relative shifts between 
different samples determined during the same measurement run (i.e. in the same environmental conditions) are compared.

Chemiresistor sensor devices were manufactured on the graphene on $\mathrm{SiC}(\mathrm{EG} / \mathrm{SiC})$ structures by deposition of Pt contact pads and mounting onto a 16 pin sensor header with integrated heater and temperature sensor (see inset in Fig. 2a). Experimental details of the sensor preparation are reported elsewhere [6]. Gas sensing measurements were conducted under laboratory conditions, using an in-house gas mixing system that comprised mass flow controllers (Bronkhurst High-tech B.V. Netherlands, model F-201C-RA-11-V 100 ml/min). Sensing characteristics in terms of sensor signal, response and sensitivity [12] were studied through the detection of $\mathrm{NO}_{2}$ concentrations ranging from $10 \mathrm{ppb}$ to $500 \mathrm{ppb}$, and $\mathrm{CO}, \mathrm{H}_{2}$, and $\mathrm{NH}_{3}$ concentrations ranging from 40 parts per million (ppm) to $500 \mathrm{ppm}$.

The carrier gas (the background gas during test pulses and the gas present at the sensor surface in between test pulses) for all of the gas exposure tests was simulated air (20\% oxygen, $80 \%$ nitrogen). The total flow was maintained constant at $100 \mathrm{ml} / \mathrm{min}$. The temperature of the sensors during gas testing was varied from room temperature (RT) to $100^{\circ} \mathrm{C}$. The resistance was measured using a Keithley 2000 multimeter configured in the two-wire mode.

\section{Results and discussion}

Figure 1 presents SKPM maps showing surface morphology and surface potential for as-grown graphene (a) and after sputter deposition of nanostructured $\mathrm{Au}$ of $\approx 5 \mathrm{~nm}(\mathrm{~b})$ and $\approx 2 \mathrm{~nm}(\mathrm{c})$, and Pt of $\approx 5 \mathrm{~nm}(\mathrm{~d})$. The graphene morphology is characterized by wide terraces due to the SiC step-bunching during the growth, whereas the differing contrasts in the surface potential map correspond to areas of single- or bilayer graphene (1LG, 2LG), due to their differing work functions [13].

After Au deposition the morphology is rougher due to the formation of Au grains (see inset in Fig. 1b). However, the surface potential still shows sharp contrast between $1 \mathrm{LG}$ and $2 \mathrm{LG}$, meaning that the electronic properties of the surface remain those of graphene as opposed to those of a metal, which would have a uniform surface potential. While the contrast between $1 \mathrm{LG}$ and $2 \mathrm{LG}$ is still visible after metallization, the value of the surface potential difference has dropped from about $35 \mathrm{meV}$, which is typically measured for as-grown EG [13], to about $15-20 \mathrm{meV}$ for $2 \mathrm{~nm}$ of $\mathrm{Au}$ an to $5-10 \mathrm{meV}$ for $5 \mathrm{~nm}$ of $\mathrm{Au}$. This difference in surface potential likely arises from different carrier concentrations in the graphene before and after metallization, altering the work functions of 1LG and 2LG differently. For the sample decorated with Pt the situation is different; the 
morphology indicates that Pt wets the graphene surface and forms a continuous porous film, and the surface potential shows an almost uniform distribution, indicating that the Pt screens the graphene surface.

Decoration with thin layers of $\mathrm{Au}$ and $\mathrm{Pt}$ was also found to alter the carrier concentration of the graphene. Work function measurements indicate that both $\mathrm{Au}$ and $\mathrm{Pt}$ n-dope the graphene (lower the work function and thus increase the Fermi level, $\left.\mathrm{E}_{\mathrm{F}}\right)$. The as-grown $\mathrm{EG} / \mathrm{SiC}$ is n-type doped due to electronic coupling with the $\mathrm{SiC}$ substrate [14]. The carrier concentration in EG/SiC varies depending on the growth conditions [15], but in our material it is normally in the range of $10^{12} \mathrm{~cm}^{-2}[13,16]$. This doping can become an issue for chemiresistor sensors if gas interactions withdraw enough electrons for the Fermi level to cross over the Dirac point where the conduction band and valence band meet, bringing about a transition from n-type to p-type conduction and as a consequence a change in the sensor response direction [6]. The relative shifts (compared to an as-grown sample) in $\mathrm{E}_{\mathrm{F}}$ due to the metallization, determined from the measured work function differences, along with corresponding carrier concentrations (calculated from $\Delta \mathrm{E}_{\mathrm{F}}$ ) are summarized in table 1 . As can be seen, $\Delta \mathrm{E}_{\mathrm{F}}$ is larger for decoration with Au compared to Pt. Intuitively one would assume that the crossover point from n- to ptype doping would be when the metal work function $\left(\phi_{\mathrm{M}}\right)$ is equal to that of graphene $(4.5 \mathrm{eV})$. However, it was found that both $\mathrm{Pt}\left(\phi_{\mathrm{M}} \approx 6.1 \mathrm{eV}[17]\right)$ and $\mathrm{Au}\left(\phi_{\mathrm{M}} \approx 5.5 \mathrm{eV}[17]\right) \mathrm{n}$-dope the graphene. This result is in disagreement with a study of Giovannetti et al., in which theoretical calculations based on DFT predicted n-type doping for Au and p-type doping for Pt [17]. However, it should be pointed out that the study of Giovannetti et al. investigated dense metal films and not thin, porous layers of a few nm.

From table 1 it can be inferred that the shift in $\mathrm{E}_{\mathrm{F}}$ due to charge transfer from the deposited metal depends on the metal thickness and the difference between $\phi_{\mathrm{M}}$ and $\phi$, where a larger difference results in less n-type doping. This indicates that the type of metal and the metallization thickness may be optimized to tune the graphene carrier concentration.

Figure 2 shows the response at $\mathrm{RT}$ and $100^{\circ} \mathrm{C}$ to ppb pulses of $\mathrm{NO}_{2}$ for sensors based on as-grown graphene (a), graphene with $5 \mathrm{~nm}$ of $\mathrm{Au}(\mathrm{b})$, and with $5 \mathrm{~nm}$ of $\mathrm{Pt}(\mathrm{c})$. The response is defined as $\mathrm{S}=\mathrm{R} / \mathrm{R}_{0}$, where $\mathrm{R}$ is the resistance under test gas exposure and $\mathrm{R}_{0}$ is the resistance in the carrier gas. As seen in Fig. 2, the sample covered with $\approx 5 \mathrm{~nm}$ of $\mathrm{Au}$ (Fig. $2 \mathrm{~b}$ ) gives a significantly faster response to ppb concentrations of $\mathrm{NO}_{2}$ compared to the as-grown graphene (Fig. 2a) and the response is significantly larger than for the graphene with $\approx 5 \mathrm{~nm}$ of Pt (Fig. 2c). This result can likely be explained by the differing morphologies and surface potential distributions as observed in Fig. 1. In the Au layer there are large areas that can be termed 'three-phase boundaries', where an approaching molecule can interact simultaneously with the Au and the graphene surface, which both increases 
the active sensing area and potentially alters the surface chemistry by providing additional and different types of adsorption sites, in turn increasing the response. Also in the $\approx 5 \mathrm{~nm}$ Pt covered sample there are such three-phase boundaries, but their total area is smaller, leading to a (smaller) response that is mostly governed by gas molecules interacting with the porous $\mathrm{Pt}$ and reaction products diffusing through the Pt to the Pt-graphene interface.

In the investigated range, $\mathrm{RT}$ to $100^{\circ} \mathrm{C}$, the temperature was not found to affect the selectivity, whereas the response magnitude and the response and recovery times decreased with increasing temperature. The response and recovery times towards $50 \mathrm{ppb} \mathrm{NO}_{2}$ at $100^{\circ} \mathrm{C}$ for the three sensors in Fig. 2 are summarized in table 2. The effect of $\mathrm{Au}$ and $\mathrm{Pt}$ decoration on the response and recovery times appears to be a significant improvement compared to the as-grown EG/SiC. In general the improvement is stronger for the case of Au than for Pt. From table 2 it is clear that the improvement is much more evident in the recovery times than in the response times; the magnitude of the improvement depends on how the response and recovery times are defined. The response time is normally defined as the amount of time required to reach a certain percentage of the saturated response, e.g. to reach 30\% (T30), 60\% (T60) or 90\% (T90) of the full sensor response. Conversely, the recovery time is defined as the time it takes to get rid of a certain percentage of the response. The calculated values for T30, T60, and T90 are reported in table 2 .

Figure 3 shows the selectivity of the sensor based on $5 \mathrm{~nm}$ of Au by comparing the response towards $\mathrm{NO}_{2}$ (30, 50, 100, 400, and $500 \mathrm{ppb}), \mathrm{NH}_{3}(40$ and $50 \mathrm{ppm}), \mathrm{CO}(500 \mathrm{ppm})$, and $\mathrm{H}_{2}(250 \mathrm{ppm})$ at $\mathrm{RT}$ and $100^{\circ} \mathrm{C}$. As can be seen there is no response to neither $\mathrm{H}_{2}$ nor $\mathrm{CO}$, which is in contrast to as-grown graphene which has a small response towards both (response curve not shown here). The response to $\mathrm{NH}_{3}$ instead is in the same range as for as-grown graphene, with a sensitivity that is approximately two orders of magnitude lower than for $\mathrm{NO}_{2}$ (e.g. the response to $400 \mathrm{ppb} \mathrm{NO}_{2}$ is of a similar magnitude as the response to $40 \mathrm{ppm}$ of $\mathrm{NH}_{3}$ ).

The changes in sensor response (sensitivity, speed of response, and selectivity) upon metallization may be due to the generation of different reaction paths or new adsorption sites created by the metal decoration, e.g. due to the breaking of $\mathrm{C}-\mathrm{C}$ bonds in the graphene to functionalize the surface, or due to the aforementioned threephase boundaries. Fully understanding the cause(s) of the altered sensor response will be the topic of a future investigation; modifications of the surface bonds will be studied by X-ray photoelectron spectroscopy, and chemical reaction products at the sensor will be studied by downstream mass spectrometry.

Further investigations aimed at optimizing the deposition are required and are underway. Surface modifications using other materials such as iridium, iridium oxide and vanadium oxide are also being explored. 
It is expected that decoration with different metals or metal oxide nanostructures will allow careful targeting of selectivity to specific molecules.

\section{Conclusion}

Epitaxial graphene on $\mathrm{SiC}$ was decorated with thin layers of nanostructured $\mathrm{Au}$ or Pt. It was found that the graphene carrier concentration can be tuned by the choice and thickness of the deposited metal. This knowledge can be used to avoid a change in the response direction of graphene chemiresistor gas sensors that may occur due to a change from n- to p-type conduction. Gas sensor measurements showed that decoration with metal nanostructures can enhance the sensitivity, response/recovery times and selectivity towards nitrogen dioxide.

The effect depends on the choice and nanostructure of the metal.

\section{References}

[1] F. Bonaccorso, Z. Sun, T. Hasan, \& A. C. Ferrari, Nature Photonics 4 (2010) 611 - 622.

[2] J. Rafiee, M. A. Rafiee, Z.-Z Yu, and N. Koratkar, Adv. Mater. 22 (2010) 1-4

[3] F. Schedin, A. K. Geim, S. V. Morozov, E. W. Hill, P. Blake, M. I. Katsnelson, K. S. Novoselov, Nat Mater. 6 (2007) 652-655.

[4] G. Chen, T. M. Paronyan, and A. R. Harutyunyan, Appl. Phys. Lett. 101 (2012) 053119.

[5] J. T. Robinson, F. K. Perkins, E. S. Snow, Z. We, P. E. Sheehan, Nano Lett. 8 (2008) 3137.

[6] R. Pearce, T. Iakimov, M. Andersson, L. Hultman, A. Lloyd Spetz, R. Yakimova, Sensors and Actuators B $155(2011) 451$.

[7] M. G. Chung, D. H. Kim,H. M. Lee,T. Kim,J. H. Choi,D.K.Seo,J.-B.Yoo, S.-H. Hong,T. J. Kang, Sensors and Actuators B 166- 167 (2012) 172- 176.

[8] S. Mao, S. Cui, G. Lu, K. Yu, Z. Wen, and J. Chen, J. Mater. Chem. 22 (2012) 11009.

[9] Y.-H. Zhang, Y.-B.Chen, K.-G.Zhou, C.-H.Liu, J. Zeng, H.-L. Zhang, Y. Peng, Nanotechnology 20 (2009) 185504.

[10] R. Yakimova, C. Virojanadara, D. Gogova, M. Syvaäjaärvi, D. Siche, K. Larsson, L. I. Johansson, Mater. Sci. For. 565-568 (2010) 645.

[11] T. Burnett, R. Yakimova, and O. Kazakova, Nano Lett. 11 (2011) 2324-8.

[12] A. D’Amico, C. Di Natale, IEEE Sens. J. 1 (2001) 183-190. 
[13] J. Eriksson, R. Pearce, T.Iakimov, C.Virojanadara,D.Gogova, M.Andersson, M. Syväjärvi,A. Lloyd Spetz,R. Yakimova, Appl. Phys. Lett. 100 (2012) 241607.

[14] S. Kopylov, A. Tzalenchuk, S. Kubatkin, and V. I. Fal’Ko, Appl. Phys. Lett. 97 (2010) 112109.

[15] J. L. Tedesco, B. L. VanMil, R. L. Myers-Ward, J. M. McCrate, S. A. Kitt,P. M. Campbell, G. G. Jernigan,

J. C. Culbertson, C. R. Eddy, and D. K.Gaskill, Appl. Phys. Lett. 95 (2009) 122102.

[16] A. Tzalenchuk, S. Lara-Avila, A. Kalaboukhov, S. Paolillo, M. Syväjärvi,R. Yakimova, O. Kazakova, T. J.

B. M. Janssen, V. Fal'ko, and S. Kubatkin, Nat. Nano. 5 (2010) 186-189.

[17] G. Giovannetti, P.A. Khomyakov, G. Brocks, V.M. Karpan, J. van denBrink, and P. J. Kelly, Phys. Rev. Lett.101 (2008) 026803. 

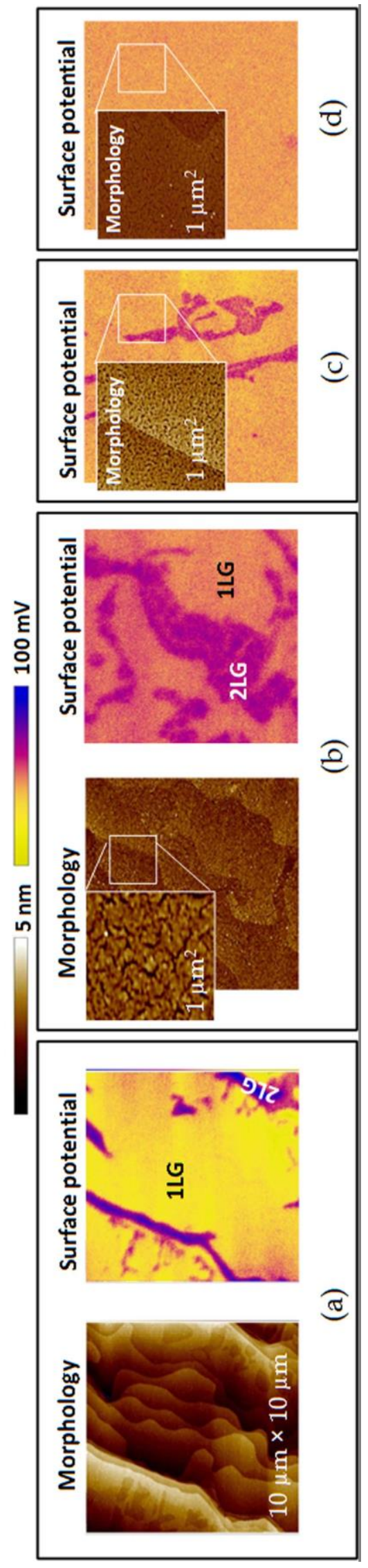

Fig. 1: Effects of metallization on morphology and surface potential. Graphene surface morphology and surface potential for the as-grown sample (a) and after deposition of $\approx 5 \mathrm{~nm}(\mathrm{~b})$ and $\approx 2 \mathrm{~nm}$ (c) of nanostructured Au, and $\approx 5 \mathrm{~nm}$ of $\mathrm{Pt}(\mathrm{d})$. The scan size is $10 \mu \mathrm{m} \times 10 \mu \mathrm{m}$ (insets are $1 \mu \mathrm{m} \times 1 \mu \mathrm{m}$ ). 

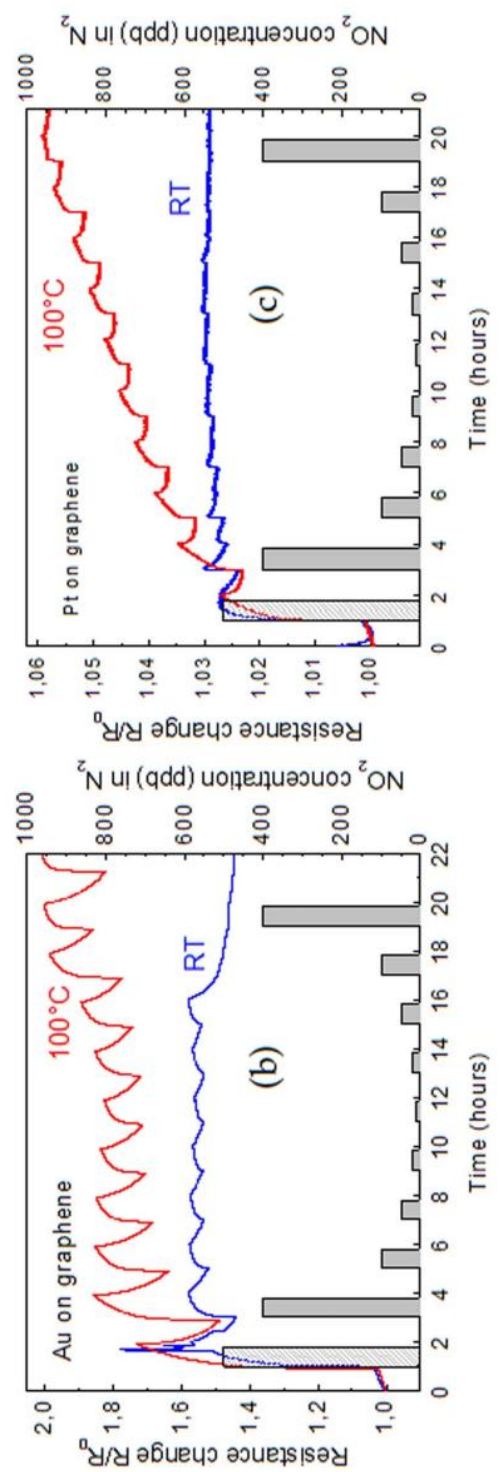

${ }^{2} \mathrm{~N}$ ul (qdd) uop!enuəsuos ${ }^{2} \mathrm{ON}$

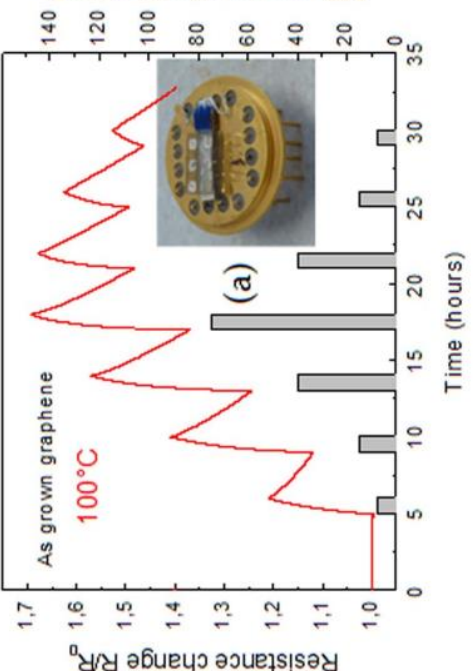

Fig. 2: Gas sensor response to ppb concentrations of $\mathrm{NO}_{2}$. Response at $\mathrm{RT}$ and $100^{\circ} \mathrm{C}$ to $\mathrm{NO}_{2}$ concentrations ranging from $10 \mathrm{ppb}$ to $500 \mathrm{ppb}$ for as-grown graphene (a), graphene decorated with $5 \mathrm{~nm}$ of $\mathrm{Au}$ (b) and with 5 $\mathrm{nm}$ of Pt (c). Due to very small response, the sensor signal at RT for the as-grown graphene is not shown. The inset in (a) shows a photo of one of the sensors. 


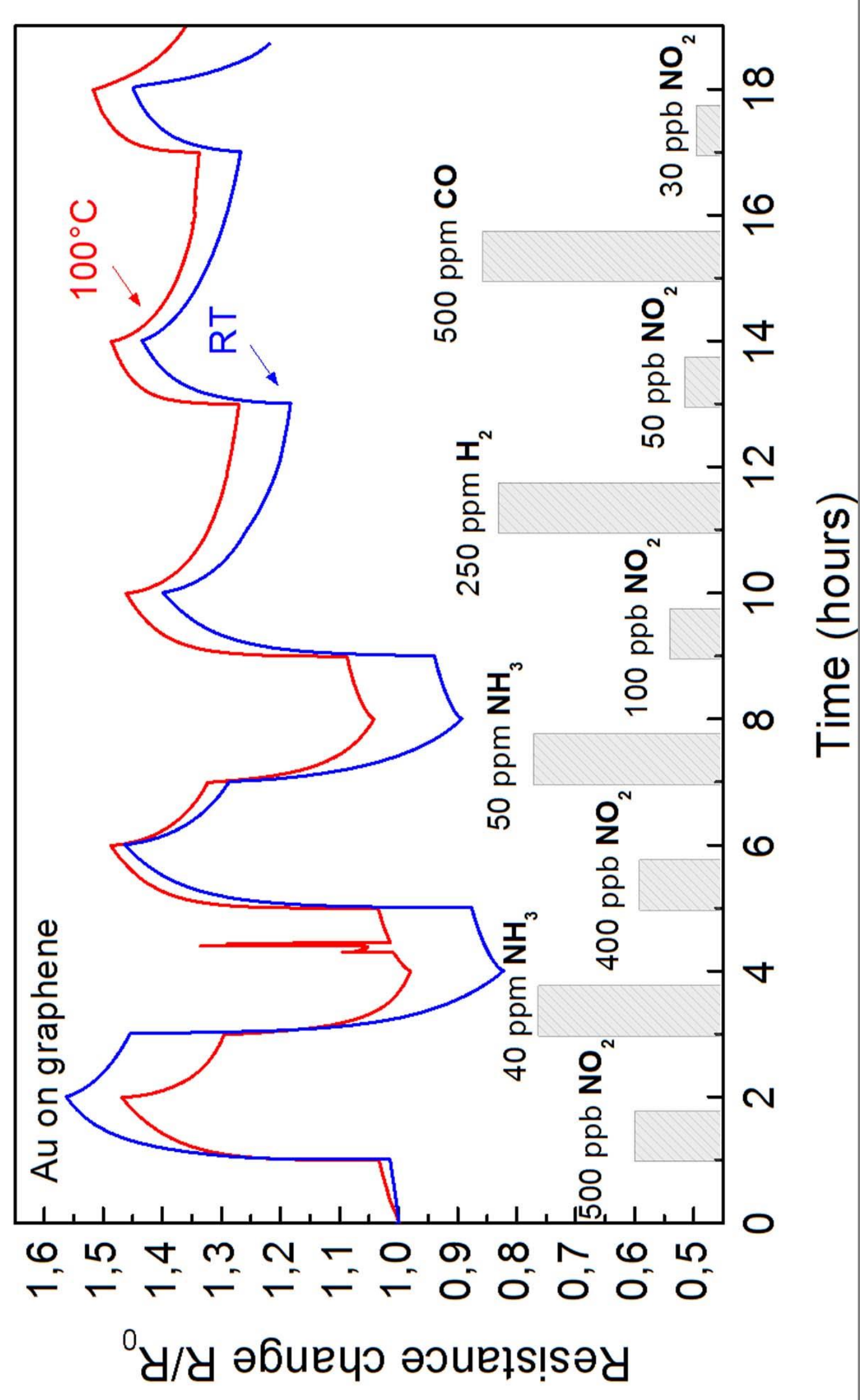

Fig. 3: Gas selectivity. Response of Au-decorated graphene towards $\mathrm{NO}_{2}, \mathrm{NH}_{3}, \mathrm{H}_{2}$ and $\mathrm{CO}$ at $\mathrm{RT}$ and at $100^{\circ} \mathrm{C}$. 
Table captions:

Table 1: Effect of $\mathrm{Au}$ and Pt decoration on the graphene carrier concentration, $N$. $N$ was calculated from the correlation between the change in Fermi energy and the graphene density of states [17].

Table 2: Response and recovery times for three different graphene surfaces towards $50 \mathrm{ppb}^{\mathrm{NO}} \mathrm{O}_{2}$ at $100^{\circ} \mathrm{C}$.

Tables:

\begin{tabular}{|c|c|c|c|c|c|}
\hline Sample & $\Delta \mathbf{E}_{\mathrm{F}}(\mathrm{meV})$ & $N\left(\mathrm{~cm}^{-2}\right)$ & & & \\
\hline As-grown $(\phi=4.5 \mathrm{eV})$ & 0 & $2.0 \times 10^{12}[16]$ & & & \\
\hline $\mathrm{Pt}, 2 \mathrm{~nm}\left(\phi_{\mathrm{M}}=6.1 \mathrm{eV}\right)$ & +45 & $2.17 \times 10^{12}$ & & & \\
\hline $\mathrm{Pt}, 5 \mathrm{~nm}\left(\phi_{\mathrm{M}}=6.1 \mathrm{eV}\right)$ & +123 & $3.3 \times 10^{12}$ & & & \\
\hline $\mathrm{Au}, 2 \mathrm{~nm}\left(\phi_{\mathrm{M}}=5.5 \mathrm{eV}\right)$ & +40 & $2.14 \times 10^{12}$ & & & \\
\hline $\mathrm{Au}, 5 \mathrm{~nm}\left(\phi_{\mathrm{M}}=5.5 \mathrm{eV}\right)$ & +273 & $8.4 \times 10^{12}$ & & & \\
\hline As-grown & \multicolumn{2}{|c|}{ Response Time (min) } & \multicolumn{3}{|c|}{ Recovery Time (min) } \\
\hline As-grown & $\mathrm{Au}, 5 \mathrm{~nm}$ & $\mathrm{Pt}, 5 \mathrm{~nm}$ & As-grown & $\mathrm{Au}, 5 \mathrm{~nm}$ & Pt, $5 \mathrm{~nm}$ \\
\hline 30 & 1.5 & 2.3 & 316 & 14 & 14,8 \\
\hline 23 & 9 & 11 & 834 & 47 & 49 \\
\hline 99 & 74 & 42 & 2136 & 135 & 175 \\
\hline
\end{tabular}

